
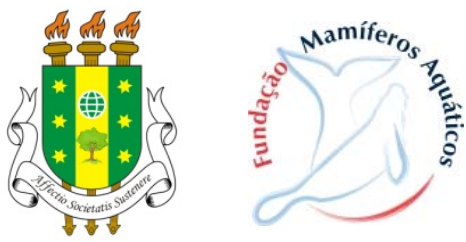

Natural:Resources

Journal homepage:

www.arvore.org.br/seer

\section{INTOXICAÇÃO POR AGROTÓXICOS NA SUB-BACIA DO NATUBA, MUNICÍPIO DE VITÓRIA DE SANTO ANTÃO (PE), BRASIL}

\section{RESUMO}

A pesquisa foi realizada na região do Baixo Natuba, município de Vitória de Santo Antão - PE, Brasil, que é conhecida pela produção de hortaliças com a utilização de diversos tipos de agrotóxicos. Foram realizadas visitas para identificar e diagnosticar como era procedido o manejo de agroquímicos pelos produtores rurais da agricultura familiar. Posteriormente foram coletadas 36 amostras de sangue dos produtores rurais por uma enfermeira cadastrada no Conselho Regional de Enfermagem - CRM. O material recolhido foi analisado pelo Laboratório Central de Saúde Pública - LACEN PE para aferir os níveis da enzima Butiril Colinesterase (BuChe) e Autil Colinesterase (AChe) que são possíveis indicadoras de intoxicação aguda e crônica por agrotóxicos, especificamente por organofosforados e carbamatos. Desse modo, as análises mostraram que $53 \%$ dos agricultores estavam com níveis abaixo do considerado normal, sendo a ocorrência maior dos "resultados indesejáveis" nas mulheres, das quais $67 \%$ apresentaram resultado abaixo do normal enquanto os homens apresentaram $33 \%$ de seu contingente abaixo do normal, sinalizando possível intoxicação por agrotóxicos nessa região. Assim faz-se necessária intervenção urgente do governo para averiguação das causas e investir na prevenção e tratamento por meio de seus diversos órgãos competentes.

PALAVRAS-CHAVE: Agroquímicos; Saúde do Trabalhador; Ecotoxicologia.
Natural Resources, Aquidabã, v.3, n.2, Set 2013.

ISSN 2237-9290

\section{SECTION: Anais do Congresso} Internacional de Ecotoxicologia Marinha (ECOMAR 2013)

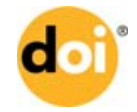

DOI: 10.6008/ESS2237-9290.2013.002.0040

Rogéria Mendes do Nascimento

Instituto Federal de Educação, Ciência e Tecnologia de Pernambuco, Brasil

http://lattes.cnpq.br/2783592629711288

mendes.nascimento@hotmail.com

Suzana Maria Gico Lima Montenegro Universidade Federal de Pernambuco, Brasil http://lattes.cnpq.br/7831378362627809 suzanam@ufpe.br

Marília Regina Costa Castro Lyra Instituto Federal de Educação, Ciência e Tecnologia de Pernambuco, Brasil

http://lattes.cnpq.br/8377604450079156 mrlyra@uol.com.br

\section{José Aleixo da Silva}

Universidade Federal Rural de Pernambuco, Brasil http://lattes.cnpq.br/5674098794412714 jaaleixo@uol.com.br

\section{João Clodoberto da Silva}

Sociedade Pernambucana de Cultura e Ensino, Brasil http://lattes.cnpq.br/4508595520254439 clodobertobeto@yahoo.com

Jonathas Gomes de Carvalho Marques Instituto Federal de Educação, Ciência e Tecnologia de Pernambuco, Brasil http://lattes.cnpq.br/5660568289427068 jonathasgomes@hotmail.com

Received: 01/04/2013

Approved: 15/06/2013

Reviewed anonymously in the process of blind peer.

\section{Referencing this:}

MARQUES, J. G. C.; NASCIMENTO, R. M.; LYRA, M.R.C. C.; MONTENEGRO, S. M. G. L.; BURGER, D.; ALBUQUERQUE, P.; SILVA, J. C.. Intoxicação por agrotóxicos na sub-bacia do Natuba, municipio de Vitória de Santo Antão (PE), Brasil. Natural Resources, Aquidabã, v.3, n.2, p.45, 2013. DOI: http://dx.doi.org/10.6008/ESS2237$\underline{9290.2013 .002 .0040}$ 